\section{P1-168 SLEEP DISTURBANCES AND A RISK OF MYOCARDIAL INFARCTION IN MALES AGED 25-64 YEARS IN RUSSIA (MONICA-PSYCHOSOCIAL)}

\author{
doi:10.1136/jech.2011.142976d.61
}

\begin{abstract}
1,2E Gromova, ${ }^{*} 1,2 \mathrm{~V}$ Gafarov, ${ }^{1,2} \mathrm{~A}$ Gafarova, ${ }^{1,2}$ I gulin. ${ }^{1}$ Collaborative laboratory of Epidemiology Cardiovascular Diseases Siberian Branch of the Russian Academy of Medical Sciences, Novosibirsk, Russia; ${ }^{2}$ Institute of Internal medicine the Siberian Branch of Russian Academy of Medical Sciences, Novosibirsk, Russia
\end{abstract}

Background We aimed to investigate the influence of sleep disturbance on the 10-year risk of myocardial infarction (MI) in men aged 25-64 years in Russia.

Materials and Methods Within the framework of the WHO program "MONICA-psychosocial" a representative sample of men aged 25-64 years was surveyed in 1994 (657 persons). Sleep disturbance were measured at baseline using the MONICA-psychosocial scale. Incidence new MI cases were ascertained using systematic surveillance the 10-year follow-up. Cox-proportional regression model was used for an estimation of RR.

Results Two thirds of the subjects who experienced their first MI referred to their sleep as "sleep disturbances". The 10-year RR of MI in men aged 25-64 years was 2.8 times higher $(p<0.05)$ in those whose sleep was described as "poor" vs those with "good" sleep. RR of MI in men aged 25-44 years was 9.25 times higher $(p<0.0001)$ in those whose sleep was described as "poor" vs those with "good" sleep. In the 45-64 year age group these differences were insignificant. RR of MI in men with sleep disturbances was higher in widowers, divorced men, with low social support level men, men with only primary education, working class men, and pensioners.

Conclusion The results demonstrate that sleep disturbances present a social problem and contribute to the risk of MI in young men.

\section{P1-169 EPIDEMIOLOGICAL SURVEILLANCE (ES) OF CONGENITAL SYPHILIS (CS) IN HOSPITALS: THE EXPERIENCE OF THE SANTA CASA DE SÃO PAULO (SCSP)}

doi:10.1136/jech.2011.142976d.62

\author{
I A Guibu, * M J P Rujula. Santa Casa SP Hospital, Sao Paulo, Brazil
}

Introdution The maternity services are essential for ES for CS. SCSP is a university hospital of São Paulo City, Brazil, It is, located in the central area of the city. Are seen at SCSP populations at high risk of infection by sexually transmitted diseases (STD), such as sex workers, injecting drug users and homeless.

Objetive To analyse the reported cases of congenital syphilis in SCSP, from 1999 to 2010.

Methods Through the surveillance system, data were obtained for all children born between 1998 and 2010 in the SCSP.

Results Were reported 555 cases of CS during the study period; considering the number of deliveries we have an average of 46.3 cases SC/year and 2.6 by 100 deliveries CS. The average age of mothers was 29 years old (ranging from 11 to 46 years) and only $6.1 \%$ had more than 7 years of schooling; $59 \%$ of pregnant women attend prenata, but these only $49 \%$ had seven or more visits, and only $13.8 \%$ were diagnosed with syphilis during pregnancy, but the treatment of pregnant women or partners was not considered adequate.

Conclusion The analysis of the data reflects the quality of prenatal care offered; Our Monitoring Service is the most notify CS in São Paulo state, probably by the population at risk for STDs that it serves, it is necessary that those responsible for improving maternal health actions for these segments of the population. The ES is very important for the control of CS assisting in planning, control and evaluation of actions.

\section{P1-170 TOBACCO USE AMONG UAE NATIONALS}

doi:10.1136/jech.2011.142976d.63

${ }^{1} \mathrm{C}$ Hajat, ${ }^{*}{ }^{2} \mathrm{M}$ Al-Houqani. ${ }^{1}$ Department of Public Health \& Research, Health Authority, Abu Dhabi, United Arab Emirates; ${ }^{2}$ Faculty of Medicine \& Health Sciences, UAE University, Abu Dhabi, United Arab Emirates

Introduction Tobacco use is a major public health problem worldwide yet it is not well-studied in the UAE. We aimed to study the prevalence and patterns of tobacco consumption among UAE nationals.

Methods We investigated 170409 Nationals aged $\geq 18$ years $(46 \%$ males, $54 \%$ females) in a population-based screening program in $\mathrm{Abu}$ Dhabi residents from April 2008 to June 2010.

Results The prevalence of smoking was $24.2 \%$ in males and $0.78 \%$ in females and highest in males aged 20-29 (27.4\%) and 30-39 years (28.2\%). Mean age (SD) of smokers was 32.8 (11.1) years, 32.7 (11.1) in males and 35.7 (12.1) in females. The mean age of onset of smoking was 22.2 (7.8) years overall, 22.4 (8.3) in cigarette smokers, 20.9 (6.7) in pipe (midwakh) smokers, 23.9 (8.1) in shisha smokers and 23.5 (8.4) in cigar smokers. Mean duration of smoking for cigarettes, shisha, pipes and cigars was 11, 8, 9 and 11 years, respectively. After controlling for age and gender, smoking was associated with (OR, 95\% CI): overweight (0.9, 0.89 to 0.96$)$, obesity $(1.1,1.06$ to 1.14$)$, central obesity (1.04. 1.00 to 1.07$)$, diabetes $(1.08,1.01$ to 1.14$)$, hypertension (1.1, 1.07 to 1.17$)$, dyslipidemia $(\mathrm{OR}=1.4,1.35$ to 1.44$)$ and family history of cardiovascular disease $(\mathrm{OR}=1.7,1.54$ to 1.77$)$ but not pre-diabetes, past history of heart disease or stroke.

Conclusion Smoking is predominant among young males. The relatively young age of onset of smoking pipes (midwakh) is of particular concern. Comprehensive tobacco control laws targeting the young population are needed.

\section{P1-171 A SCALABLE APPROACH TO IMPROVING DEATH NOTIFICATION IN THE EASTERN MEDITERRANEAN REGION: LESSONS FROM ABU DHABI}

doi:10.1136/jech.2011.142976d.64

0 Harrison, A Al Mannaie,* F Ahmed. Health Authority of Abu Dhabi, Abu Dhabi, United Arab Emirates

Background Although accurate death notification is critical, data quality is inconsistent in many health systems. There are additional difficulties in countries in the Eastern Mediterranean Region with burial typically within $24 \mathrm{~h}$ of death (limiting post-mortem examination). The law in United Arab Emirates (UAE) mandates vital event notification. In 2007, the Health Authority-Abu Dhabi (HAAD) revised death notification in the Emirate. We report the results of these improvements plus the 2009 Abu Dhabi Mortality statistics including historical comparisons.

Methods The death notification system was systematically evaluated using the lean process-engineering model. Issue analysis and process redesign involved consultation with public health experts, forensic specialists, and faculty from UAE University. A novel notification form and a simple quality assurance process were developed. The combination of the form and process interventions were piloted before implementation across Abu Dhabi.

Results The proportion of unknown cause of death decreased 39\% over 4 years, (2006: 25.1\%, and 2009: 15.3\%). There were 2917 deaths notified in Abu Dhabi during 2009 (of which 33\% were UAE Nationals). Overall crude mortality rate was 1.52 per 1000 and agestandardised death rate (using WHO world standard population) was 473.2 per 100000 .

Conclusions Abu Dhabi mortality data compares favourably with global statistics in terms of quality and completeness. Substantial 